\title{
The role of citizens in emergency management systems in the Czech Republic
}

\author{
J. Rehacek, J. Dlabka, B. Baudisova \& P. Danihelka \\ Faculty of Safety Engineering, VSB, \\ Technical University of Ostrava, Czech Republic
}

\begin{abstract}
Safety is one of the major priorities in European society. In order to ensure a better quality of life and to remain proactive even during emergencies, effective risk management is needed. Current trends clearly indicate a shift from a passive role of citizens as recipients of help to empowerment and effective self-protection. This paper aims to provide insights into the present state of citizen engagement in the risk management systems within the field of civil protection in the Czech Republic. An analysis of citizens' roles has been conducted and the deficiencies of the current system are discussed along with the identification of possibilities for improvement. Results indicate that the citizen's role within the Czech Republic emergency management system is rather ambiguous. On a theoretical level, stated in the strategy policy guidelines, citizens are perceived as an integral part of the system and, as such, should be empowered to self-protection. But practical implementation leads us to the conclusion that citizens are rather subjects of rescue, passive recipients of help from the side of trained professionals and the major focus is still concentrated on the public authority bodies rather than on citizens. This ambiguous state is particularly visible within the risk communication efforts and the future implications should be discussed further.
\end{abstract}

Keywords: emergency management, risk communication, civil protection, disasters.

\section{Introduction}

Human society has been constantly exposed to disasters and emergencies throughout its existence. Large-scale disasters and emergencies are major life events for both communities and individuals. Handling these types of events used 
to be predominantly within the competences of the affected communities and individuals, but in recent decades, it is far more often a competence that is delegated to special professionals who are better trained and prepared than normal citizens to deal with all possible types of such emergencies.

Emergency management system has to serve both as a system that reflects the nature of a hazard and its possible consequences and as a system that reflects the natural behaviour of affected communities. The major issue is the dichotomy between the prescribed roles of citizens and trained professionals within the emergency management system's hierarchical structure. If the emergency management systems are biased, then they may be ineffective. Overemphasizing the competences of authorities in the event of emergencies is contrary to the requirements for resilience and sustainability, because if the system's means and resources do not meet the needs of the affected communities, then we may have a real emergency.

The main objectives of this paper are to evaluate the emergency management system in Czech Republic with an emphasis on citizen engagement and to determine whether or not the current emergency system reflect on the means, potential and needs of citizens in case of emergencies. The first part of this paper provides a review of human behavioural reactions to disasters. The second part describes the emergency management system in the Czech Republic. The third part focuses on an analysis of the national legislation and how it affects the potential role of citizens. In the fourth section, the discrepancies between optimal emergency management and the current emergency management are defined and described. The last part summarizes possible future implications.

\section{Citizens' behaviour during emergency situations}

In recent years, terms such as "modern disasters" or "disasters of the 21 st century" have been more frequently used than ever. The number of disasters and emergencies has been increasing, but more importantly, so has their severity [1].

Smet et al. [1] inspected randomly chosen disasters and emergencies in which their complexity over time increases, as well as the increased likelihood that there will be events for which emergency management systems are not designed or prepared.

For such scenarios, it is crucial to incorporate and to reflect the skills, competencies and resources of the citizens to support an increase of capacity that leads to a more resilient society and sustainable emergency management systems. Many papers have been published on the topic of human behaviour during disasters and emergencies (e.g. [2-4]). The main objective is to resolve and to elucidate the misunderstandings about human behaviour during those emergencies that are reportedly confused with irrational and rather improper reactions.

Based on those findings, requirements for emergency systems that accept and are derived from behavioural science literature have been formed. It is important to have knowledge about hazards, but also to accept and to foster knowledge about the human behaviour of citizens in times of emergency. Emergency systems that do not reflect those principles are predestined to fail and have to be considered 
ineffective [1]. Future hazards for human society resulting from complex interactions between economical, technical and social factors represent a new challenge for redefined emergency management systems. Such systems have to establish and also recognize all possible roles taken by communities on all levels and to organize stakeholders accordingly [5].

But the question still remains, to what extent are citizens capable of self-rescue and of rescuing and helping others? According to Helsloot and Ruitenberg [4], the behaviour of modern citizens is probably still the same as that of their ancestors. Data from real emergencies indicates that most of the lives saved during emergencies are saved not by trained professionals, but by ordinary citizens. The number of people rescued by trained professionals is reported to be only onefourth of those who need to be helped [4]. This implies that citizens are the basic units who are in large extent capable of helping not only themselves, but also others. Therefore, the individuals and the communities with their capacities, means, resources, knowledge, and relationships should be perceived as an essential and independent part of the critical infrastructure of emergency management systems [6]. The citizens are first on the scene and respond to and rescue individuals. In addition, they also protect the property from being further destroyed [2].

A study conducted by Donahue [7] states that many of the public officials perceive citizens very differently than the citizens perceive themselves. Public officials assume that people are poorly informed, unaware of how to react in case of an emergency, that citizens cannot be trusted in their overall judgment and that they are significantly less-prepared that people think they are. Public officials also tend to attribute the lack of preparedness on the procrastination, rejection and overall laziness of citizens, while the citizens claim that they lack the necessary information.

Patterns of human behaviour recorded during emergencies indicate that the claim of irrational citizens is not true. Dynes [8] formulated a hypothesis of situational altruism. This is a specific form of altruism that arises from emergency situations. Dynes claims that this behaviour originates from the presence of victims on-site and also assumes that a lack of sufficient resources in a particular situation is needed for situational altruism to be exhibited. Situation altruism is then formed as an auxiliary form of behaviour that is not observable outside of emergency situations [8].

These findings show us that there is much more going on during emergencies than is usually assumed by public authorities and some experts. There are new roles being formed, the old roles are being expanded, time-honoured organizational schemes are being changed and values are being re-prioritized. All those changes appear to be chaotic and confusing due to their very rapid progress, but acknowledging that a rational explanation exists behind those actions is essential for coping with disasters and emergencies.

Only then it can be observed that citizens generally react rationally and correctly. They seek important information and in most cases they do everything they are capable of to cope with an emergency situation. Victims of disasters do 
not react irrationally, they just react differently than what public officials and some experts assume [9].

That led to the conclusion that a hierarchical emergency management system is not fully effective and systems supporting and enabling decision-making at lower levels should be adopted instead. The generally-used emergency management systems that are based on bureaucracy, a top-down management and on hierarchical structure have to be improved and updated. Accordingly, bureaucratic emergency management systems display properties such as: predefined objectives and goals, formal structures implemented to coordinate actions and activities on all levels and a stratified division of labour in order to prevent a repetition of tasks and general confusion [10].

In addition, all procedures and principles should be designed, developed and accepted by all members of the organization in order to effectively react to the chaotic environment. Takeda and Helms $[10,11]$ showed that with regard to such events as Hurricane Katrina and tsunamis, bureaucratic structures are dysfunctional and ineffective.

Perrow [12] brings about the idea of non-robust systems implying "inelegant" structures. He suggests perceiving emergencies as a process of weakening the organizational systems from the point of disruption, which is the catastrophic event. Robust systems of this kind require an "inelegant" system of management and governance. This means that organizational structures should not be slim, centralized and positions in it should not be specialized. This correlates with RouxDufort [13] who perceives an emergency as a systemic weakening of the organizational structures to the point of disruption caused by an emergency event. Current modern technological and informational systems allow for decentralization, but they are usually designed to support centralized management [12].

So again, a better definition of roles within society is needed to be able to coordinate and to organize actors on all possible levels in order to improve coping with such threats [14]. According to the "upper echelons theory" [15], top managers structure a situation so that decisions reflect their world view. They oversimplify the world in order to understand it. Roux-Dufort [13] perceives their arrogance as a result of the difference between the complexity of the situation and what managers perceive as simplified reality.

Dynes [3] made a distinction between classic bureaucratic crisis management systems based on paradigm $\mathrm{C}^{3}$ (chaos, command, control) and effective crisis management, where continuity should be emphasized over chaos and coordination and cooperation should be more significant than command and control [3]. For emergency planning, it is possible to define theoretical applicable fields [16]. List of potential factors affecting emergency response is defined by Thévenaz and Resodihardjo [17].

Emergency planning is also often biased (burdened), which leads to a loss of effectiveness, meaning that preparations are focused on situations that do not reflect reality. One example is panicked behaviour, which is far less common than people think it is [18-21]. For example, preparedness in the USA is perceived as an opportunity on the individual level and includes activities such as being 
informed about relevant risks, preparing emergency communication plans and preparing tools for helping each other during emergencies. In some cases, it has been proved that people who do not have trust in the government have a $50 \%$ probability that they will obey government orders [22].

To ensure that people are able to take care of themselves, they need applicable and actual information upon which they can base their decisions. Without that information, people will still make decisions and judgments, but those decisions will be reasonable and appropriate only from the subjective point of view and will stand up to the viewpoint of experts. Disaster risk management structures come into consideration in cases of residents who are unable to help themselves or cannot be rescued by fellow citizens [23]. In their study, Di Mauro et al. [24] showed that people do have an interest in preparation and prevention activities with regard to Seveso facilities, but this is hindered by insufficient risk communication and low awareness about risks. Murphy [25] states that emergency management systems in communities should not stand against governmentinduced emergency management systems, but should complement them.

\section{Analysis of the roles of citizens in emergency systems}

The analysis has been conducted by reviewing of strategic documents and through the Czech national legislative related to the civil protection. There are many acts and decrees related to the citizen protection and to the emergency system. In the selected documents there have been systematically searched parts and key words describing primarily or secondarily rights and obligations of citizens and structures by which they are included to the emergency system. The findings of the analysis have been compared to the findings described above. The differences are discussed along with outlining of their common cause.

Regarding the strategic documents, there is one major document strictly related to the civil protection. It is the conception for population protection, which is being processed in multiyear interval. In the conception for years 2006 to 2013 [26] has been explicitly stated: "Basic element of civil protection system is informed and educated citizen, who can react on taken precautions, will contribute to selfprotection and to protection of others".

In a more recent conception [27], this statement is no longer present, but civilians are perceived as part of a system which needs to be educated and informed as well as to be given a set of responsibilities. There is however stated that civilians are responsible partly for their own safety. Generally civilians are being taken into account as autonomous unit, who is able to react individually and contribute to its own safety.

The Czech Republic, due to its rather convenient geographical location and thanks to its natural conditions, is not commonly affected by major disasters with extreme consequences in life losses. Of the most notable ones over the past 20 years are floods, windstorms and landslides. In spite of the effects on property and the need for substantial evacuations during the floods of 1997 and 2002, there is no experience with any other large-scale disasters with an acute threat to a large number of people. 
The national civil emergency system is fairly new and modern. Civil protection has undergone massive development. Initially, during the cold war, the civil protection system was built mostly as a protection against consequences of war, as in (not only) other communistic countries. After 1989 change of regime to democratic, the civil protection system was slightly updated, but there was only partial effort to focus more specifically on this matter. This changed after 1997 when large-scale floods showed everyone that the systems were inefficient, which led to completely new legislative packages that defined emergency and crisis situations, competencies etc. The basic structure of the new system was profiled in 2000 .

The emergency system is two-tiered - generally, there is emergency planning and preparedness with crisis planning. The first case of preparedness is for "emergency situations", which means natural phenomena along with industrial emergencies [28]. Preparedness is mainly defined as cooperation between rescue units on all levels, called the integrated emergency system (IRS). Cooperation is defined as joint operations and chain of command and covers the area of emergency planning. In the Czech Republic, the government level has two basic types of emergency plans - external emergency plans of nuclear [29] or chemical facilities [30] and the emergency plans of entire regions [29]. Procedures during the management of emergencies focus mostly on onsite management, which is the equivalent of an incident command system [31,32]. On higher levels, cooperation is managed by information and operation centres - these are communication centres for emergency calls located in most cases in main regional fire stations [28].

The second tier is called crisis management, which focuses on situations that are beyond the capabilities of solely-integrated rescue systems [33, 34]. Crisis management is mainly on the local or regional level and only in some cases at national level. Within this system is a crisis management staff, which consists of regular officials who should be organizing anti-crisis activities and measures in times of crisis. Legislatively, crisis management enables actions that would otherwise not be possible (such as work obligations, closing entry to areas and restrictions on the right to strike).

The role of citizens as described in law is defined in both emergency management system and crisis management system independently. Within the emergency management system, the role of the citizens is defined by the responsibilities, rights and obligations of citizens in general and also by the institutes that act as a secondary units of the IRS in cases of emergencies [28]. It is explicitly stated that an integral part of the IRS are "civil protection organizations", non-governmental organizations (NGOs) and civic associations, all of which could be of help in rescue and response activities. Their participation is planned only before emergencies and they are activated only if their assistance is needed. By legal rights, those subjects are obliged to obey orders from the incident commander [28].

The main principle of citizen integration in the emergency preparedness system and in emergency plans is to inform and educate citizens of the possible risks and threats and to inform them about planned measures $[28,35]$. In addition, in an 
emergency, they must obey orders from the legal authorities responsible for coordinating IRS (the incident commander in most cases). Citizens are, within preparedness efforts, perceived as a value that should be protected and also a part of the IRS, which means they have an obligation to obey direct orders. Legislation clearly states that there is a right to be informed about risks in the time before any emergency, but only before the event occurs [28]. Warnings and information received during an emergency is an integral part of emergency plans, but only marginally mentioned in law. The executive decree [29] also explicitly states that part of coordination is securing of the closure of the event surroundings and forbidding entry by everyone who is not necessary.

In developed emergency plans [29, 30], the most attention is focused on a description of the territory along with the hazard, on a list of allocated forces and resources and in the end, specific actions to be taken. Emergency plans do not include citizens as autonomous units. They can participate in rescue operations, but only if they are coordinated by someone from IRS (the incident commander) or to be controllably rescued (being evacuated, sheltered, etc.).

Crisis management is the difference between emergency situations and crises given by the policy decision. The state of a crisis is a situation where an emergency situation goes beyond the possibilities of IRS and for which authority is needed to declare a state of crisis that will allow officials to take extraordinary precautions. In the Czech Republic, there is a total of 4 states of crisis [33, 34, 36]. Two of them are civil and usable during civil emergencies [34] and two of them are military-based, which focus on threats to democracy [33] and/or on war [36]. The main task of crisis management is to preserve the functionality and continuity of state administration. The measures are mainly based on the economical level (the planned duty of defined subjects to provide services and resources), keeping those subjects functioning (critical infrastructure protection) and last but not least, on defined management systems.

Managing a crisis situation is taken care of by crisis management staffs, which are defined on all levels of state administration and they consist of elected officials and public servants from different levels. The chair of the crisis staff is typically the highest-ranking authority (Mayor, Governor, etc.). Crisis staff can be used even in an emergency (as a command for IRS) to coordinate large-scale emergencies, but this option is not often used [34].

The role of citizens in this system is also very limited. Citizens are perceived passively as someone who should be protected or coordinated; this is the same as in the case of emergencies. Citizens have the right to be informed about information needed for crisis management and planning, and supposed to tolerate limitations derived from crisis actions to be taken, to carry out the work obligation and to provide material means. The term "voluntary assistance" is an extended form of assistance when addressing an emergency situation. Local emergency authorities may decide that citizens have to do a certain job in a certain place for a certain period of time [34].

Crisis planning doesn't include its functioning citizens to be active parts at all. Sections of crisis plans that are formed from descriptions of danger or defined precautions include only lists of institutions and entrepreneurs conducting 
commercial activities suitable for aiding the defined means described above [37]. First and foremost, these are subjects of critical infrastructure, but the idea is not to involve everyone who can help, but rather manage the provision of resources and services in an emergency situation. The crisis plan itself does not include any option to incorporate local, non-governmental organizations or the community.

\section{Major issues identification}

The main question is why is there such a discrepancy between academic findings and the current state in the Czech Republic? One factor is a lack of major disasters, so the updated management systems have not yet been needed for large-scale sudden crises, and without this experience, it is hard to develop functioning structures.

The Czech Republic, because of its favourable geographical location, is spared from many large-scale disasters such as earthquakes, hurricanes and large landslides. In the past 20 years, there has been only one type of disaster that has led to disaster risk management improvement: floods. With regard to the findings listed above, these possible problems have been identified:

1. The system is optimized for small-scale emergencies and disasters, not for crises and emergencies that are beyond the experience of the IRS. Saying that the IRS is ineffective is an overstatement and is not true. Only the IRS structure meets the needs and situations that do not go beyond its common possibilities or assets.

2. Citizens are perceived as passive receivers who have to be cared for. Safety and security in the Czech Republic is mostly understood as a granted service to be provided to citizens.

3. Authorities responsible for crisis and emergency management ignore human behaviour in emergencies. In crisis and emergency plans, as well as in legislative and methodological documents, there is no mention of how the specific behaviour of citizens is to be taken into account. The absence of such practice is obviously the reason for this situation, but according to Dynes [3] it is the main obstacle to reaching effective crisis management.

4. The system is too bureaucratic and non-transparent. The two-step emergency and crisis management system is to some extent confusing and is not easy to understand it due to complicated and overlapping competencies. There are too many plans and the goal for managers is mostly to meet legal requirements. The whole system of emergency planning is strongly derived from military practice what is according to Dynes [3] neither appropriate nor effective.

5. There is no further practice with risk communication with the citizens during emergencies and preparedness. Communication is conducted only as a legal requirement but, it does not reflect human behaviour. It is in contrast with well-functioning specific early warning and information systems in floods preparedness [38], which only confirms the prerequisite 
that experience and closeness to the issue is a major factor for enhancing the system and that sufficient information activities and warning is of great importance for the ability to cope with disasters.

6. Science and research in crisis management appear to be internalized and derived from experience, which leads to oversimplifying the adaptation of legal requirements without further analysis. Even though there is a wide range of experts and academics in this field, the field is perceived as mostly technical and socio-economic and psychological components are being ignored or at least not employed sufficiently.

7. The positive message is, that new Conception of Citizens Protection till 2020 put emphasis on citizen active participation and stakeholder involvement, as well as on communication and education system improvement.

\section{Discussion and conclusions}

New emerging threats, such as terrorism, new types of (or a combination of) global-change induced disasters, along with low probability threats lead to the question whether or not the Czech Republic is, along with other countries, facing new challenges properly. It leads to questioning the effectiveness and functionality of the prevention and response system for emergencies for which we are not yet prepared and for which current resources would probably not be sufficient. This further leads to question about whether the emergency management system still works as a rather bureaucratic hierarchical structure without considering human behaviour rather than reflecting real crisis (situations that we are not accounted for) which requires constant revisions, searching for better solution and learning from others.

With current systems in the EU, it is not necessary to address the protection of territories within each member state. A promising solution is to renounce hierarchic structures and to use the incident command system and incident command management instead, which will guarantee a sustainable life of the citizens [39]. It is needed to accommodate a shared philosophy of disaster and/or emergency preparedness, which is the same for the EU [39].

First, citizens have to be taken into account as a part of complete systems, as they have the responsibility and also the ability to rescue themselves and to help to rescue others. It is possible and appropriate to let them participate and to engage them not only in the preparedness phase, but also in ongoing disasters [40]. A crucial tool for achieving these goals is a functioning effective risk communication system.

One of the possible ways to improve risk communication is to employ modern information technologies. A high level of engagement during emergencies is not a new thing, but thanks to information technology, the roles are far more transparent and there are many more opportunities for citizen to be put into action [41], including active management. Modern technologies allow for more active engagement of citizens if there is better access to the Internet and with 
incorporating mobile technologies, mobile phones, text and multimedia messages especially when combined with GPS [41].

A hopeful solution would be an avoidance of hierarchical and pseudo military structures and not using incident command systems and incident command management. Better employing of NGOs could be one solution, too.

\section{Acknowledgement}

The contribution has been supported by the Program of Security Research of the Czech Republic 2010-2015 as a part of Project No. VG20132015131.

\section{References}

[1] Smet, H., Lagadec, P., Leysen, J., Disasters out of the box: a new ballgame? Journal of Contingencies and Crisis Management, 20 (3), pp. 138-148, 2012.

[2] Perry, R.W., Lindell, M.K., Understanding citizen response to disasters with implications for terrorism. Journal of Contingencies and Crisis Management, 11(2), pp. 49-60, 2003.

[3] Dynes, R.R.., Community emergency planning: false assumptions and inappropriate analogies. International Journal of mass Emergencies and Disasters, 12 (3), pp. 141-158, 1994.

[4] Helsloot, I., Ruitenberg, A., Citizen response to disasters: a survey of literature and some practical implications. Journal of Contingencies and Crisis Management, 12 (3), pp. 98-111, 2004.

[5] Olsen, O.E., Kruke, B.I., Hovden, J., Societal safety: Concept, borders and dilemmas. Journal of Contingencies and Crisis Management, 15 (2), pp. 69-79, 2007.

[6] Barnes, J., Newbold, K., Humans as a critical infrastructure: Public-private partnerships essential to resiliency and response. First IEEE International Workshop on Critical Infrastructure Protection, Los Alamitos, CA, USA, pp. 75-83, 2005.

[7] Donahue, A.K., Ready or not? How citizens and public officials perceive risk and preparedness. Public Management Research Conference, Syracuse, New York, June 2-4, 2011.

[8] Dynes, R.R., Situational Altruism: Toward an Explanation of Pathologies in Disaster. Assistance Research presentation, Xiii World Congress of Sociology, Germany, 1994.

[9] Quarantelli, E.L., Community crises: an exploratory comparison of the characteristics and consequences of disasters a riots. Journal of Contingencies and Crisis Management, 1 (2), pp. 67-78, 1993.

[10] Takeda, M.B., Helms, M.M., "Bureaucracy, meet catastrophe": Analysis of Hurricane Katrina relief efforts and their implications for emergency response governance. International Journal of Public Sector Management, 19 (4), pp. 397-411, 2006.

[11] Takeda, M.B., Helms, M.M., "Bureaucracy, meet catastrophe": Analysis of the tsunami disaster relief efforts and their implications for global 
emergency governance. International Journal of Public Sector Management, 19 (2), pp. 204-217, 2006.

[12] Perrow, C., Organizing to reduce the vulnerabilities of complexity. Journal of Contingencies and Crisis Management, 7 (3), pp. 150-155, 1999.

[13] Roux-Dufort, C., Is crisis management (only) a management of exceptions? Journal of Contingencies and Crisis Management, 15 (2), pp. 105-114, 2007.

[14] Olsen, O.E., Kruke, B.I., Hovden, J., Societal safety: Concept borders and dilemmas. Journal of Contingencies and Crisis Management, 15(2), pp. 69$79,2007$.

[15] Hambrick, D.C., Mason, P.A., Upper echelons: The organization as a reflection of its top managers. Academy of management review, 9 (2), pp. 193-206, 1984.

[16] Herzog, R.J., A model of natural disaster administration: naming and framing theory and reality. Administrative Theory \& Praxis, 29 (4), pp. 586-604, 2007.

[17] Thévenaz, C., Resodihardjo, S.L., All the best laid plans...conditions impeding proper emergency response. International Journal of Production Economics, 126 (1), pp. 7-21, 2010.

[18] Quarantelli, E.L., Panic behaviour in fire situations: Findings and a model from the English language research literature. Fourth Joint Panel Meeting of the United States Japan Panel on Fire Research to be held in Tokyo, Japan, 1979.

[19] Quarantelli, E.L., The sociology of panic. International encyclopaedia of the social and behavioral sciences. Pergamon Press: New York, pp. 11020$11030,2001$.

[20] Quarantelli, E., The behaviour of panic participants. Sociology and Social Research, 41(3), pp. 187-194, 1957.

[21] Quarantelli, E.L., The nature and conditions of panic. American Journal of Sociology, 60(3), pp. 267-275, 1954.

[22] Lasker, R.D., Redefining readiness: Terrorism planning through the eyes of the public. University at Albany, School of Public Health, Centre for Public Health Preparedness, 2005.

[23] Scholtens, A., Jorritsma, J., Helsloot, I., On the Need for a Paradigm Shift in the Dutch Command and Information System for the Acute Phase of Disasters. Journal of Contingencies and Crisis Management, 22(1), pp. 3951, 2014.

[24] Di Mauro, C., Bouchon, S., Torretta, V., Industrial risk in the Lombardy Region (Italy): What people perceive and what are the gaps to improve the risk communication and the participatory processes. Chem. Eng. Trans, 26, pp. 297-302, 2012.

[25] Murphy, B.L., Locating social capital in resilient community-level emergency management. Natural Hazards, 41 (2), pp. 297-315, 2007.

[26] Ministry of Interior, Conception of Population Protection till 2013 with a possible overlaps until the year 2012. Government of Czech Republic: Praha, 2008. 
[27] Ministry of Interior, Conception of Population Protection till 2020 with a possible overlaps until the year 2030. Government of Czech Republic: Praha, 2013.

[28] Parliament of the Czech Republic, Act No. 239/2000 Coll., on integral rescue system and on the amendment of some laws, as amended. Collection of Laws of the Czech Republic, 2000.

[29] Ministry of Interior, Decree No. 328/2001 Coll., on certain details of providing of integrated emergency system. Collection of Laws of the Czech Republic, 2001.

[30] Ministry of Interior, Decree No 103/2006 Coll., which designates fundamentals for designating an accident planning $\mathrm{z}$ one and the scope and method of preparing an external emergency plan. Collection of Laws of the Czech Republic, 2006.

[31] Alexander, D., Principles of emergency planning and management. Oxford University Press, Oxford: New York, 2002.

[32] Bigley, G.A., Roberts, K.H., The incident command system: Highreliability organizing for complex and volatile task environments. Academy of Management Journal 44 (6), pp. 1281-1299, 2001.

[33] Parliament of the Czech Republic, Constitutional Act No. 110/1998 Coll., on security of the Czech Republic, as amended by the Constitutional Act No. 300/2000 Coll. Collection of Laws of the Czech, 1998.

[34] Parliament of the Czech Republic, Act No. 240/2000 Coll., on crisis management and on the amendment of some laws, as amended. Collection of Laws of the Czech Republic, 2000.

[35] Ministry of Interior, Decree No. 380/2002 Coll., on the preparation and implementation of civil protection. Collection of Laws of the Czech Republic, 2002.

[36] Czech National Council, Act No. 1/1993 Coll., Constitution of the Czech Republic. Collection of Laws of the Czech Republic, 1993.

[37] Government of the Czech Republic, Government Decree No. 462/2000 Coll., which implements the provisions of Sec. 27(8) and Sec. 28(5) of Act No. 240/2000 Coll., on Emergency Management and Amendment to Some Acts. Collection of Laws of the Czech Republic, 2000.

[38] Höppner, C., Buchecker, M., Bründl, M., Risk communication and natural hazards. CapHaz project. Birmensdorf, Switzerland, 2010.

[39] Boin, A., Ekengren, M., Preparing for the world risk society: towards a new security paradigm for the European Union. Journal of Contingencies and Crisis Management, 17 (4), pp. 285-294, 2009.

[40] Roberts, N., Public Deliberation in an Age of Direct Citizen Participation. The American Review of Public Administration, 34 (4), pp. 315-353, 2004.

[41] Palen, L., Liu, S.B., Citizen communications in crisis: anticipating a future of ICT-supported public participation, Proceedings of the SIGCHI Conference on Human Factors in Computing Systems. ACM, New York, USA, pp. 727-736, 2007. 